\title{
Masculinidades, sexualidades y género
}

\author{
Masculinities, sexualities and gender
}

\section{IVÁN SAMBADE*}

Resumen: Los estudios de las masculinidades surgieron en el último cuarto del siglo pasado como una respuesta positiva frente a los cambios sociales que habían ocasionado las políticas feministas y los estudios de la mujer. Originariamente, estos estudios se centraron en explicar cómo la socialización patriarcal inducía a los hombres a desarrollar una masculinidad basada en la sujeción social y personal de las mujeres. Posteriormente, sus análisis se complejizaron a partir del desarrollo de la teoría de género y de nuevas disciplinas académicas basadas en el estudio de la sexualidad. La masculinidad se conceptualizó como un hecho social plural y jerárquico. El concepto de masculinidades señala una pluralidad de categorías sociales de hombres diferentes en función de la intersección del género con otros ejes de identificación como la raza, la clase social o la sexualidad. Estas masculinidades se encuentran sumidas en relaciones jerárquicas entre sí, pero, a su vez, reproducen conjuntamente la estructura social de discriminación de las mujeres. Asimismo, el desarrollo de nuevas y plurales perspectivas de análisis generó también un vigente debate sobre el cambio de los hombres hacia masculinidades más libres e igualitarias. En este trabajo, presentamos una propuesta para la transformación social de los hombres basada en el universalismo democrático, la ética del cuidado y la perspectiva del desarrollo humano.

Palabras clave: Género, masculinidades, sexualidades, igualdad, cambio social.

Abstract: Masculinity studies appeared in the last quarter of the last century as a positive response to the social changes that had caused the feminist politics and the Women's

* Iván Sambade: Docente Universidad de Valladolid, Valladolid, España. Código ORCID: org/00000003-0514-1948. Contacto: ivansambade@gmail.com 
Studies. Originally, these studies focused on explaining how the patriarchal socialization led men to develop a masculinity based on social and personal subjection of women. Subsequently, the development of gender theory and of new academic disciplines based on the study of sexuality made their analysis more complex. Masculinity was conceptualized as a plural and hierarchical social fact. The concept of masculinities signals a plurality of different social categories of men in relation to the intersection of gender with other axes of identification such as race, social class and sexuality. These masculinities are immersed in hierarchical relationships with each other, but, in turn, they replicate together the social structure of discrimination of women. Additionally, the development of new analytical perspectives also generated a current discussion about the change of men toward freer and egalitarian masculinities. In this study, we present a proposal for the social transformation of men based on democratic universalism, the ethics of care and human development perspective.

Keywords: Gender, masculinities, sexualities, equality, social change.

\title{
Introducción: el feminismo de segunda ola y la crisis de la masculinidad.
}

\begin{abstract}
A pesar de la ingente cantidad de literatura científica que actualmente podemos encontrar sobre el concepto de masculinidades, su problematización en el entorno académico es relativamente reciente. El concepto de masculinidad $^{1}$, definido no como una identidad esencial o biológica, sino como una construcción sociocultural que se desarrolla en un contexto histórico determinado, aparece sistematizado por primera vez en los análisis de las autodenominadas feministas radicales ${ }^{2}$. Desde finales de los años sesenta, pensadoras como Kate Millett (1975) comenzaron a explicar cómo las mujeres eran socializadas en la subordinación frente a los hombres, mientras que éstos lo eran en el ejercicio social del poder, mediante un sistema implícito de dominación que, como tantos otros, sería ineficaz si no contara con el respaldo de la violencia ${ }^{3}$. Este sistema, el
\end{abstract}

\footnotetext{
${ }^{1}$ Actualmente, el término masculinidad se emplea en singular para hacer referencia a la masculinidad patriarcal. Es decir, a la masculinidad resultante de un proceso de enculturación que se produce en sociedades caracterizadas por la primacía social de los hombres y la discriminación sistémica de las mujeres. Estudios como los del antropólogo David Gilmore (1994) han señalado que a pesar de la diversidad cultural existente entre las masculinidades de distintas sociedades tanto en el espacio como en el tiempo, todas tienen características comunes en relación con la supremacía social de los hombres sobre las mujeres. Esta observación encaja con los estudios de Marvin Harris (1981), quien ya en 1971, señaló que todas las sociedades conocidas, tanto del presente, como del pasado, son sociedades patriarcales.

${ }^{2}$ El adjetivo radical alude al término latino radix (raíz). De este modo, el feminismo radical se definía por la búsqueda de las causas estructurales de la discriminación y la desigualdad de las mujeres.

${ }^{3}$ La violencia estructural contra las mujeres, hoy en día denominada violencia de género. Una de sus manifestaciones más cruel y extendida es la violencia que ejercen los hombres contra las mujeres en sus relaciones personales.
} 
sistema de dominación masculina, fue denominado patriarcado. De este modo, las feministas norteamericanas recogieron el testigo de Simone de Beauvoir ${ }^{4}$, instaurando todo un campo de estudios académicos caracterizados principalmente la hermenéutica feminista de la sospecha y por el enfoque constructivista en el análisis de la identidad. Son los estudios académicos de la mujer, posteriormente denominados estudios de género 5 .

Los estudios de las masculinidades surgen como una reacción positiva frente a los estudios feministas o estudios de la mujer (Kimmel, 2008). De hecho, inicialmente estuvieron financiados dentro de proyectos de investigación feministas (actualmente lo siguen estando en muchos casos) y, por lo general, siguen compartiendo su enfoque y sus principales líneas de análisis. Pero, al mismo tiempo, los estudios de las masculinidades respondían a un fenómeno social intrínsecamente relacionado con los cambios generados por el movimiento feminista de segunda ola; la denominada crisis de la masculinidad.

Desde una perspectiva popular, la crisis de la masculinidad describe la situación de inseguridad y tedio vital que los hombres occidentales habrían comenzado a vivir como consecuencia de los cambios sociales impulsados por las políticas feministas. A finales de los años ochenta, los hombres comenzaron a ser representados como víctimas sociales por la cultura popular ${ }^{6}$, hasta el punto de que la violencia masculina llegó a ser entendida como una consecuencia del "acecho social" que estaban viviendo (Segal, 2008). Asimismo, los discursos académicos sobre la crisis de la masculinidad también apuntaron hacia los cambios sociales impulsados por el feminismo. La incorporación de las mujeres al mercado de trabajo (con la consiguiente ruptura de su sujeción en la esfera social privada y el reconocimiento explícito de sus derechos en la esfera social pública), las políticas de discriminación positiva, las leyes de protección específica frente a la violencia de los hombres y el cuestionamiento general de la legitimidad del poder/control social de los hombres en tanto que sexo biológicamente superior, habrían sido las causas fundamentales de la crisis existencial de los hombres occidentales. En definitiva, la crisis de la masculinidad no sería más que el cúmulo de consecuencias personales causadas en los hombres por las tendencias de crisis de la estructura social de poder que sustenta esta identidad hegemónica: el patriarcado.

Ahora bien, la diferencia fundamental entre el análisis académico y la representación cultural de la crisis de la masculinidad era que, desde el enfoque académico, tanto el patriarcado, como las conductas masculinas que tienden a reproducirlo, fueron consideradas formas injustas de explotación y control de las mujeres; un atentado contra sus derechos humanos que se seguía (y se sigue) produciendo en

\footnotetext{
${ }^{4}$ Simone de Beauvoir sintetiza la perspectiva constructivista de la identidad sexual en su obra "El segundo sexo", con su célebre frase "la mujer no nace, llega a serlo" (De Beauvoir, 1981, p. 13).

${ }^{5} \mathrm{El}$ concepto de género describe las identidades sexuales (masculinidad y femineidad) como resultados de los procesos culturales de socialización propios de las sociedades patriarcales.

${ }^{6}$ Este fenómeno cultural comenzó en la sociedad estadounidense, para posteriormente extenderse al resto de países occidentales.
} 
modernas sociedades definidas por su auto-identificación democrática. Desde esta perspectiva, la violencia y el tedio vital de los hombres se presentan como resultados de la creencia asumida por éstos de que tienen derecho a ejercer poder sobre las mujeres (tanto en el espacio público como en el privado), sólo por el mero hecho de ser hombres. Es decir, la crisis de la masculinidad se origina en una injusta fantasía de dominación que sigue siendo alimentada por la simbología patriarcal ${ }^{7}$. De hecho, actualmente, los hombres permanecen ocupando prácticamente de forma exclusiva las altas esferas del poder político y las posiciones de decisión fundamentales dentro de las corporaciones económicas multinacionales. Contrariamente, los salarios más bajos y el trabajo a tiempo parcial predominan entre la oferta laboral destinada a las mujeres, quienes continúan asumiendo el trabajo doméstico y la crianza de los hijos e hijas en el espacio privado. De este modo, se continúa reproduciendo la desigualdad económica entre hombres y mujeres en todas las esferas sociales del poder: macro, meso y microestructurales. Como señaló el sociólogo español Josep Vicent Marqués (1991), que el patriarcado esté en crisis no significa que haya desaparecido.

Uno de los motivos por los que la cultura popular habría interpretado las críticas feministas de la masculinidad como un ataque directo hacia los hombres fue el hecho de que los primeros estudios del feminismo radical se centraron en la masculinidad patriarcal occidental como una forma universalizada de masculinidad. La forma universal de la crítica, junto con la esquematización operada por los procesos de difusión social y con el hecho de que en las sociedades receptoras seguía existiendo un imaginario androcéntrico ${ }^{8}$, contribuyeron a que la recepción de los estudios de la masculinidad por parte de los hombres occidentales se tradujera en forma de resistencia?.

La resistencia masculina frente a los cambios sociales no se produjo sólo de forma personal, sino que surgieron múltiples grupos de hombres que se unieron para presentarse como víctimas de los cambios sociales generados por las políticas feministas. Los grupos de hombres más representativos en este sentido se encuadran dentro de dos movimientos con comunes características: el movimiento de hombres Mito-Poéticos y el movimiento de hombres por los derechos de los hombres. Ambos grupos están integrados fundamentalmente por hombres blancos de clase media y, en particular, dentro del

\footnotetext{
${ }^{7}$ Por lo tanto, las crisis personales se darán en mayor medida en aquellos hombres que, encontrándose identificados con la simbología patriarcal, se sientan impotentes frente a la pérdida de espacios de poder social, particularmente de aquellos en los que obtenían control sobre las mujeres.

${ }^{8} \mathrm{El}$ androcentrismo es el sesgo por el cual las personas perciben a lo masculino y a los hombres como más valioso y superior que lo femenino y las mujeres. Como explicó Pierre Bourdieu (2005), esta visión se obtiene de forma natural en las sociedades estructuradas por el binarismo sexual masculino/femenino y por la supremacía social de los hombres respecto de las mujeres. Es decir, en las sociedades patriarcales.

${ }^{9}$ Esta resistencia se podría explicar como un proceso inconsciente operado por el androcentrismo social. Al menos en primera instancia, una visión androcéntrica de la realidad impediría a los hombres percibir sus privilegios sociales respecto de las mujeres. Esto no excluye el hecho de que existan hombres que, conscientes de sus privilegios sociales y de su injusticia, no sólo se resisten a participar en los cambios hacia la justicia de género, sino que operan activamente para acrecentar la desigualdad social entre hombres y mujeres.
} 
movimiento mito-poético, se habla abiertamente de reencontrar la masculinidad profunda, una identidad natural que las nuevas tendencias sociales estarían reprimiendo. Su principal representante es el escritor y dramaturgo Robert Bly, quien en 1990 publicó con gran éxito de ventas su obra Iron John.

Ahora bien, los cambios sociales impulsados por las políticas feministas también han generado grupos de hombres que apoyan la lucha de las mujeres por la igualdad social y reconocen la necesidad de responsabilizarse frente a las estructuras de discriminación sexual de las actuales sociedades democráticas. Son grupos de hombres que se declaran anti-sexistas, pro-feministas e igualitaristas: los grupos de hombres por la igualdad (Bonino, 2008). Una de las campañas más importantes impulsadas por hombres por la igualdad es la White Ribbon Campaing -WRC- (campaña del lazo blanco). Esta campaña, iniciada entre otros por el sociólogo Michael Kauffman en $1991^{10}$ (un año después de la masacre de Montreal), ha vinculado en todo el mundo a grupos de hombres que denuncian públicamente la violencia machista contra las mujeres. El objetivo común de esta denuncia es que ningún agresor pueda sentir complicidad masculina en sus acciones delictivas contra las mujeres, ya que estos se suelen justificar a través de falsos mitos y creencias patriarcales sobre las mismas.

\section{Masculinidades y género.}

A partir de los análisis del feminismo radical sobre las identidades sexuadas, se obtuvo una primera definición del concepto de masculinidad patriarcal. La hermenéutica feminista puso de manifiesto que, a lo largo de la cultura occidental, ha existido una rígida división sexual del trabajo que ha deparado la exclusión de las mujeres de la esfera social pública. Auto-investidos como los sujetos agentes de la esfera social pública, los hombres construyeron un discurso sobre la humanidad en el que las cualidades denominadas femeninas, las que las mujeres habían desarrollado a través del ejercicio del cuidado y el trabajo doméstico (sensibilidad, dulzura, intuición...), fueron definidas como condiciones propias de la naturaleza animal, ergo cualidades humanas de segundo orden. Por el contrario, las atributos necesarios para el trabajo en la esfera pública (fortaleza, determinación, racionalidad...) definieron el ámbito de la Cultura, la política y el poder. Como resultado, las mujeres resultaban seres más próximos a la Naturaleza que la Cultura, lo que legitimaba y reproducía su sujeción en la esfera social privada, frente al poder social de los hombres (Fraisse, 1991). Tenemos así una definición universalista de

10 Es importante destacar que los científicos sociales dedicados al estudio de las masculinidades generalmente se sienten identificados con las posiciones de los grupos de hombres por la igualdad, formando parte de los mismos en numerosas ocasiones. 
la masculinidad en la que los hombres aparecen representados como la plenitud de la condición humana.

Identificados con la Razón, los hombres fueron representados por la cultura patriarcal como las personas capacitadas para el desarrollo del conocimiento, para el gobierno de las ciudades y para el desempeño de la actividad económica en la esfera pública (Sambade, 2010). Asimismo, su capacidad de gobierno fue legitimada en el espacio privado. En el hogar, el hombre era el patriarca: el cabeza de familia ${ }^{11}$. La masculinidad representaba (y representa) a los sujetos de éxito social como encarnación de la plenitud humana. Pero, si bien es cierto que los hombres han desempeñado históricamente el ejercicio del poder, encarnando la excelencia social, también lo es que la conducta antisocial ha tenido siempre un protagonismo casi exclusivamente masculino. Esta observación puso la violencia masculina contra las mujeres y la violencia masculina en general en el punto de mira de los análisis del feminismo igualitarista.

Existen dos argumentos comúnmente conocidos que han justificado la violencia masculina. El primero es que los hombres la ejercían bajo el deber de proteger a sus suyos. Lo hacían en el gobierno de las naciones y en sus ejércitos, protegiendo a sus ciudadanos. Y lo hacían en sus hogares, protegiendo a sus mujeres, hijos e hijas. A su vez, este argumento estaba justificado por el segundo, según el cual los hombres se encuentran biológicamente inclinados hacia el ejercicio de la violencia, lo que los situaba de modo natural en el ámbito de la defensa y del combate. En lo que respecta a este segundo argumento, múltiples estudios han puesto de manifiesto que los factores ambientales son más determinantes que los biológicos en el desencadenamiento de la violencia masculina (Sapolski, 1997). Asimismo, la superior fuerza física masculina existe como promedio, no siempre y todos los casos. Pero las objeciones al primer argumento son mucho más determinantes en el contexto de las modernas democracias occidentales. En sociedades regidas por los principios de Libertad, Igualdad y Solidaridad, en sociedades que aspiran a mantener una convivencia pacífica y justa, la única protección que necesita cualquier ciudadano o ciudadana es la que el Estado ha de ejercer sobre sus derechos legales, iguales por definición a los de cualquier otro ciudadano. Además, como muestran las estadísticas de violencia de género, es precisamente frente a los hombres, frente a quien las mujeres precisan de la protección institucional.

La violencia masculina y la violencia de género como forma selectiva de la misma tienen graves consecuencias sociales (Clare, 2002). Ambos son hechos sociales injustos que tienen el objetivo de reproducir determinadas posiciones de poder y supremacía

\footnotetext{
${ }^{11}$ David Gilmore (1994) ha explicado que la masculinidad patriarcal se constituye a partir de tres exigencias morales que él mismo ha denominado las tres P: protección, provisión y potencia. En consecuencia, un "hombre de verdad" debe fecundar a una mujer, proteger a su familia y proveer económicamente a quienes dependen de él.
} 
social, de las que los hombres no consiguen desvincularse ${ }^{12}$. Esto no constituye muestra alguna de racionalidad en un paradigma democrático regido por los derechos humanos, sino, por el contario, perpetúa una estructura social de desigualdad e injusticia: la estructura de poder patriarcal o el sistema de sexo-género ${ }^{13}$.

Una vez apuntado el concepto de masculinidad desde los estudios feministas, los teóricos y las teóricas de la masculinidad se centraron en explicar cómo la violencia, el machismo y la misoginia eran inducidas en la subjetividad de los hombres a través de su socialización en las estructuras sociales patriarcales y en su simbología androcéntrica. En esta línea, Miriam Miedzian (1995), dedicó su trabajo a analizar las causas de la socialización de los hombres en el machismo y la violencia, así como a proponer distintas políticas educativas que pudieran erradicar estos procesos. Víctor Seidler (2000) explicó cómo los paradigmas mecanicista y economicista que vertebran nuestra cultura occidental desde la Ilustración han conformado la moral y la subjetividad de los hombres mediante una identificación con la Razón que les ubica como agentes de éxito social por medio de las prácticas de control y explotación de todo aquello que ha sido identificado con la Naturaleza ${ }^{14}$. Elisabeth Badinter (1993) realizó un completo análisis de la masculinidad, en el que describió los diferentes tipos de identidad masculina que habían surgido en relación con los cambios sociales impulsados por el feminismo. Esta línea de análisis ya había sido contemplada con anterioridad por Lynne Segal (1990), quien argumentó la importancia de estudiar las diferentes masculinidades, sus causas y sus posibilidades de cambio.

Uno de los conceptos más significativos del análisis constructivista de las identidades sexuales es el concepto de género. Este concepto define las identidades sexuales (masculinidad y femineidad) como construcciones psico-sociales que se desarrollan en contextos culturales e históricos concretos, con la característica común de que en todos ellos prevalece una estructura de discriminación social de las mujeres. Por lo tanto, las identidades sexuales no son esencias o determinaciones biológicas, sino que los hombres y las mujeres adquieren su identidad de género a través de un proceso de socialización, en el que aprender a pensar, sentir y actuar de acuerdo con las expectativas socioculturales sobre la masculinidad y la femineidad presentes en una sociedad y un momento histórico concretos. De este modo, el enfoque constructivista se antoja

\footnotetext{
${ }^{12}$ Pierre Bourdieu (2005) ha explicado que la masculinidad patriarcal ha sido caracterizada por su potencia reproductora en dos sentidos: en primer lugar, como reproducción sexual; y, en segundo, como reproducción del capital social y económico; luego, de la posición de poder que se ostenta.

${ }^{13}$ El concepto de sistema de sexo-género es sinónimo del concepto de patriarcado, con la particularidad de que éste se centra más en los aspectos voluntarios de la dominación, mientras que el término patriarcado alude de forma más explícita a la estructura coercitiva de dominación masculina.

${ }^{14}$ La cultura patriarcal ha identificado a las mujeres y a todo aquello definido como femenino con la Naturaleza (Fraisse, 1991). En este sentido, la definición de la emotividad como un instinto natural supuso el desarrollo por parte de los hombres de una pragmática de control de las emociones denominadas femeninas como proceso de identificación con la masculinidad normativa. Esta represión de la emotividad es, asimismo, un proceso de socialización en el ejercicio de la violencia. Véase Sambade (2010), Seidler (2000), Bourdieu (2005) y Badinter (1993), entre otros.
} 
fundamental en la medida en que sustenta la posibilidad de transformación de las identidades que explica; luego de los hombres y de las mujeres como personas socializadas en la simbología normativa de sexo-género. En tanto que personas (sujetos libres y racionales) podemos actuar sobre nuestra conducta para modificar nuestra identidad; podemos construirnos como proyectos libres ${ }^{15}$. Asimismo, en tanto que personas (seres sociales) podemos influir en nuestra sociedad y nuestra cultura para modificar sus estructuras de subordinación y sus lógicas simbólicas, transformando así las definiciones sociales de género (la masculinidad y la femineidad) $y$, consiguientemente, las relaciones entre hombres y mujeres. La significación del concepto de género es de tal importancia que, en muchas universidades, los Estudios de la Mujer cambiaron su denominación por la de Estudios de Género (Gender Studies).

El feminismo afroamericano realizó una de las críticas al enfoque de género que mayores y más fructíferas consecuencias ha ocasionado para el desarrollo de estos estudios. La perspectiva de género fue señalada por realizar un análisis universalista que producía una exclusión de segundo orden: la de las mujeres que pertenecían a clases o etnias no hegemónicas (Jabardo, 2012). Las feministas afroamericanas apuntaron con insistencia que los estudios de género sólo representaban a las mujeres de raza blanca y clase social media-alta. Con ello, la noción de diversidad enriqueció notablemente el concepto de género, complejizándolo y completándolo, de modo que la identidad se comenzó a comprender cómo el resultado de la intersección del género con otras identificaciones como la raza, el sexo, la clase y la opción sexual.

En lo que refiere al estudio de las masculinidades, la noción de diversidad supuso una respuesta frente a las críticas de muchos hombres que no se veían representados por la masculinidad patriarcal: gays, transexuales, hombres pro-feministas o igualitarios, etc. En 1995, Raewyn Connell ${ }^{16}$ presentó uno de los conceptos más valiosos para el análisis de las masculinidades, entendidas como una colectividad de identidades que, siendo diversas, responden conjuntamente a la lógica del sistema de género-sexo: el concepto de masculinidad hegemónica. Connell (1997) incidió en la idea de que las masculinidades son configuraciones prácticas que se ubican en múltiples estructuras de relación dentro del sistema de sexo-género. Las masculinidades se encuentran entreveradas por diferentes trayectorias históricas y sociales, de modo que su configuración responde simultáneamente a distintas lógicas de poder-subordinación (de clase, raza, opción sexual), al mismo tiempo que a la de género. De este modo, sólo se pueden explicar las masculinidades analizando las relaciones de género dentro de los contextos de las clases, las razas y las opciones sexuales por separado: "hay hombres gay negros y obreros de

\footnotetext{
${ }^{15}$ La idea de que la masculinidad es una construcción centra la crítica de género en el terreno ético de la responsabilidad. Si los hombres no son agentes de desigualdad por naturaleza, entonces pueden cambiar. No son culpables por haber sido socializados como tales, pero sí responsables de cambiar para convertirse en agentes de igualdad, en personas justas.

16 Raewyn Connell es una mujer transgénero y adoptó este nombre en 2007, por este motivo sus publicaciones anteriores se encuentran firmadas con el nombre de R.W. Connell.
} 
fábrica afeminados, así como violadores de clase media y travestis burgueses" (Connell, 1997, p. 11). El objetivo de Connell es poner de manifiesto los procesos de jerarquización, normalización y marginación de las masculinidades, explicando así cómo ciertas categorías de hombres reproducen un sistema en el que, además de la dominación global de los hombres sobre las mujeres, existe un sistema dinámico de relaciones de podersubordinación entre diferentes categorías sociales de hombres (Connell y Masserschimidt, 2005).

Desde este enfoque dinámico-relacional, Connell define la masculinidad hegemónica como la configuración práctica de género que ocupa la posición de primacía en un modelo concreto de relaciones de género, una posición que está siempre sujeta a disputa. Esta configuración de género encarna la respuesta convencional respecto de la legitimidad del patriarcado, por lo que suele estar respaldada explícita o subyacentemente por la violencia; violencia masculina que sigue dos patrones: 1) La violencia que ejercen algunos hombres para sostener su dominación concreta sobre las mujeres; 2) La violencia entre hombres como política de confirmación de la masculinidad.

Connell observa que, a pesar de que la violencia se ejerce también entre los hombres como una manifestación de sus relaciones jerárquicas de dominación, simultáneamente constituye una práctica de identificación masculina frente a las mujeres. De esta forma, las distintas masculinidades jerarquizadas asumen su complicidad común en el sistema de dominación de las mujeres. Asimismo, señala que, dentro de un paradigma democrático, un sistema que precisa de violencia selectiva para mantener su estabilidad es un sistema sin legitimidad. De esta manera, Connell apunta directamente hacia las tendencias de crisis del patriarcado moderno o sistema de sexo-género.

\section{Sexualidades y Masculinidades.}

El análisis de Connell se nutrió de nuevos estudios como la teoría gay y la teoría queer. Estos y otros análisis basados en la sexualidad habían cobrado una gran trascendencia social y académica a lo largo de la década de 1990, presentando así una relevancia significativa para los estudios de las masculinidades. En 1998, Judith Halberstam publicó su obra Female Masculinity. Halberstam argumentó que las características asociadas a la femineidad y la masculinidad no son biológicas, que no están determinadas por el sexo, sino que, como expectativas socioculturales, ambas pueden ser adquiridas en diferentes grados tanto por mujeres como por hombres. Halberstam centra su análisis en la masculinidad femenina (representada fundamentalmente por las lesbianas butch y las transexuales), bajo la hipótesis de que, a pesar de haber permanecido subordinadas frente a las masculinidades de los hombres blancos, estas re-significaciones culturales de la masculinidad dominante (varón blanco heterosexual de clase media) habrían contribuido 
a la reproducción de la mística heroica de la masculinidad de forma incluso mayor que los exponentes de virilidad encarnados en los cuerpos de los primeros. Con este análisis, Halberstam criticaba la noción esencialista de la masculinidad, al mismo tiempo que mostraba que existen estrategias culturales de re-significación y re-apropiación de las posiciones sociales dominantes en el sistema de sexo-género.

Las estrategias reseñadas por Halberstam, la re-significación y la reapropiación estético-discursiva de los roles hegemónicos de la masculinidad y la femineidad (de las identidades de género) encuentran su fundamentación teórica en una de las obras más importantes de la moderna teoría feminista ${ }^{17}$; Gender Trouble. Con esta obra, Judith Butler (1990) se convirtió en la pensadora fundacional de la teoría Queer.

Basándose en las interpretaciones de Michel Foucault y Jacques Derrida sobre el poder discursivo, Butler sostiene que no existe sujeto si no lo es en el marco de un lenguaje que lo instituye como tal, sujetándolo a un campo de restricciones que son al mismo tiempo posibilidades de agencia. Asimismo, niega que existan los sexos como hechos biológicos; el sexo es una inscripción discursiva normativa al igual que el género. Las identidades sexuales son el resultado de un proceso compulsivo de socialización en la matriz heterosexual del deseo construida en el falogocentrismo ${ }^{18}$ de la cultura occidental.

Butler afirma que los términos que otorgan inteligibilidad social a lo humano se organizan desde la matriz heterosexual que distribuye las identidades y disciplina los cuerpos a través del binarismo sexual ${ }^{19}$. En esta lógica, a cada ser humano le corresponde siempre un género en virtud de su sexo, de modo que se establece una continuidad entre sexo, género, deseo y práctica sexual, consolidándose como imperativo social la complementariedad de los sexos diferentes. Simultáneamente, se instituye la sujeción masculina de las mujeres, puesto que, en el discurso falogocéntrico, el sujeto agente posee marcadas connotaciones masculinas. En consecuencia, todo aquello que aparece al margen de la coherencia de género resulta excluido, interiormente reprimido, socialmente patologizado. Son los cuerpos abyectos. Con el concepto de abyecto, Butler designa a todas aquellas personas que no disfrutan del estatus de sujeto, pero que paradójicamente definen su dominio desde el exterior ${ }^{20}$. Es la zona social de lo no narrable, lo inhabitable, lo ininteligible.

\footnotetext{
${ }^{17}$ Existe un debate académico acerca de si las obras de Butler se pueden enmarcar dentro de la teoría feminista o bien, si, por el contrario, se encuadran propiamente dentro del posfeminismo.

${ }^{18} \mathrm{El}$ falogocentrismo es la preminencia de los órdenes del falo (símbolo del poder masculino) y del logos (la Razón, concretada en los racionalismos occidentales) en la construcción simbólica de la cultura occidental. En esta lógica, los hombres son representados como sujetos de conocimiento frente a las mujeres, lo que les ubica como los agentes sociales por excelencia.

${ }^{19}$ Judith Butler sigue en este punto las conceptualizaciones de Adrienne Rich sobre la heterosexualidad obligatoria.

${ }^{20}$ Butler se refiere principalmente a personas de sexualidad no normativizada.
} 
En síntesis, el sistema heterocentrado de sexo-género, conforma siempre identidades sexuales binarias y unitarias como condición de inteligibilidad social. Estas identidades se asumen por medio de prácticas confirmatorias que crean la fantasía de coherencia y estabilidad con fines de disciplinamiento social. Pero la realidad es que la identidad se encuentra fragmentada internamente por diversos ejes de discriminación y pertenencia (raza, etnia, clase y sexo principalmente), en una dispersión de identificaciones cruzadas e inestables que resultan ocultadas por la pregnancia del núcleo identitario de género. Ahora bien, existen cuerpos abyectos; personas que, habitando el lugar de la ininteligibilidad, estando fuera de la jerarquía del sujeto, son necesarias para construir su definición desde el exterior (Butler, 1998).

En Gender Trouble, Butler (1990) explica que las personas de sexualidad no normativizada (cuerpos abyectos) no padecen neurosis tal y como se había sostenido desde la Psicología tradicional. Por el contrario, Butler entiende que las personas de sexualidad normativizada experimentan un creciente malestar en relación con su sexo y su sexualidad. Por lo tanto, para Butler, sólo cabe atreverse al cambio. Las mismas inscripciones performativas ${ }^{21}$ de género que nos constituyen en la sujeción son incompletas e inestables, de modo que, como sujetos instituidos por la invocación lingüística, encontramos un pliegue en la estructura de repetición del lenguaje desde el que ejercer nuestra agencia.

Butler explica que el lenguaje en el que somos constituidos como sujetos (hombres o mujeres) es una estructura histórica de repetición (iteración social) y diferencia (cada momento y circunstancias específicas en las que se enuncia un performativo). Los significados se consolidan por sedimentación cada vez que una inscripción performativa se repite imponiendo la norma social. Pero, a su vez, el hecho de que el performativo de género se tenga que repetir en el tiempo para producir sus efectos sociales, hace que este sea incompleto e inestable. Por lo tanto, la apertura del lenguaje performativo entraña la posibilidad de un contra-discurso (Butler, 2004). Cada repetición de un performativo contiene y oculta una diferencia respecto del original, el cual, en sentido estricto, ya era una copia (Butler, 1993). La repetición se produce en la forma de actos estilizados en el tiempo que admiten la posibilidad de ruptura o repetición subversiva del estilo. Por este motivo, Butler propone la repetición paródica como forma de resignificación discursiva de la norma social y, por ende, de resistencia frente a la misma. Sólo, así, el deseo se torna capaz de rearticular las inscripciones del dimorfismo sexual, generando nuevas posibilidades de agencia.

Desde esta perspectiva, Butler recela de las propuestas de cambio basadas en políticas de representación. La mera citación de las identidades representadas provocaría

\footnotetext{
${ }^{21}$ Siguiendo a J. L. Austin, Butler considera que el lenguaje es performativo. El lenguaje no sólo describe estados, sino que a través del habla se ejercen actos diferentes del acto de la propia enunciación. En este sentido, los conceptos de género son performativos. Es decir, cuando alguien dice "es un niño" o "es una niña", no está describiendo un estado, sino inscribiendo una identidad constreñida por normas sedimentadas en el lenguaje mediante un proceso de iteración social.
} 
su estabilización, bien generando nuevas relaciones de poder o bien reproduciendo aquellas que se han sedimentado en su semántica performativa. La propuesta de Butler es la proliferación de los géneros paródicos; una constante generación de identidades en fuga de la norma de sexo-género, de inscripciones no normativizadas en constante desplazamiento y re-significación.

Las prácticas queer se caracterizan por una parodia social de las representaciones de sexo-género (cercana a la performance teatral) que pretende transgredir la normalidad sexual, bajo el objetivo de reivindicar la legitimidad de las identidades y las prácticas sexuales no normativizadas. Para Butler, la sorprendente forma en la que los colectivos queer se han apropiado del término que se empleaba para denostar socialmente a personas de sexualidad no normativizada y lo han recontextualizado (invirtiendo sus efectos de poder) constituye un ejemplo manifiesto de que la resignificación social y política de un término es posible ${ }^{22}$. Prácticas queer como el outness (declaración pública de la propia homosexualidad), los bailes drag, la hiperfemineidad y la masculinidad transexuales y la hipervirilidad leather, entre otras, constituyen distintas parodias sociales de la normas performativas de género que revelan su carácter contingente (frente a su estatuto cosificado); luego que ponen de manifiesto la posibilidad de transformación de las identidades que inscriben.

En lo que se refiere al análisis de las masculinidades, las prácticas y los estudios queer se han centrado en mostrar que la masculinidad patriarcal, con sus atributos de control emocional, independencia, invulnerabilidad... y heterosexualidad, es en sí misma una ficción discursiva. En este sentido, Javier Sáez (2005) ha explicado que las subculturas leather y bear de la comunidad gay realizan una parodia de la masculinidad como hipervirilidad, como exceso de masculinidad, que muestra que la propia masculinidad heterosexual es en sí misma una construcción paródica. Sáez entiende que las prácticas sadomasoquistas de la cultura leather revelan precisamente que la masculinidad es vulnerabilidad. Análogamente, Calvin Thomas (2000) ha señalado que las acciones queer deberían revelar una y otra vez la dependencia de las masculinidades dominantes respecto de su exterior subordinado. El objetivo es desestabilizar la identidad masculina a través de múltiples conexiones tanto políticas como eróticas con aquellas identidades de cuya dominación depende la autoestima del hombre dominador. Dentro de esta línea pragmática, Brian Pronger (1998) ha argumentado que para desterritorializar la masculinidad fálica es necesario que los hombres se abran hacia el deseo receptivo; que estén dispuestos a ser penetrados como forma de des-masculinización del deseo. Un paso más adelante se encontraría la propuesta de la filósofa española Beatriz Preciado (2002), la contra-sexualidad: una subversión crítica del sistema de sexo-género basada fundamentalmente en la erotización sadomasoquista del ano. En opinión de Preciado, la focalización del ano como centro erótico, junto con la asunción de que el pene es sólo un

\footnotetext{
${ }^{22}$ El término queer ("raro", "rarito") se empleaba en la cultura anglófona norteamericana para referirse despectivamente a gays, lesbianas, bisexuales y personas transgénero.
} 
tipo posible de dildo entre otros (puños, brazos, picanas eléctricas...), deconstruiría el falocentrismo simbólico.

Las aportaciones de la teoría queer han sido imprescindibles para el desarrollo de los análisis de las masculinidades. La teoría queer esclarece la conexión entre la homofobia y la misoginia, revelando cómo la construcción de la masculinidad en las relaciones inter pares está interrelacionada con la construcción de la masculinidad en las relaciones entre hombres y mujeres (Kimmel, 2008). Además, la teoría queer evidencia que tanto las masculinidades heterosexuales como las masculinidades gays son construidas en la heteronormatividad. Nos encontramos así con variaciones de hombres en relación con la sexualidad, de modo que sus similitudes son más relevantes que sus diferencias. Esto pone de manifiesto que la masculinidad sigue siendo el principio organizador tanto de la conducta masculina heterosexual como de la conducta masculina homosexual (Kimmel, 2008). Finalmente, la teoría y las prácticas queer constituyen una importante línea de acción social transformadora que reivindica la legitimidad de las identidades sexuales no normativizadas. Son, por lo tanto, un importante instrumento de liberación, transgresión y transformación del eje heteronormativo del sistema de sexogénero.

Por otro lado, entiendo que la teoría y las prácticas queer son por sí mismas incapaces de generar un marco normativo de justicia social desde el que se pueda articular el cambio de los hombres hacia nuevas masculinidades igualitarias. Son un instrumento de liberación y crítica, por lo que son legítimas y muy necesarias, pero no son suficientes.

En Gender Trouble, Judith Butler propone un deambular identitario entre inscripciones no normativizadas en continuo desplazamiento y resignificación con el objetivo de liberar al deseo de la heteronormatividad. Ahora bien, la proliferación de sexos-géneros no implica por sí misma que se rompan las tramas de dominación jerárquica, sino que, por el contario, esta puede devenir en nuevas y sutiles formas de dominación. Más aún, si consideramos que, como Butler sostiene, las identidades degeneradas serán subsidiarias de las figuraciones de sexo-género precedentes (Femenías, 2003). Esto es significativamente importante para el cambio de las masculinidades, puesto que la lógica simbólica de sexo-género tienen una gran capacidad para rearticularse bajo formas y estéticas diferentes, lo que en última instancia reproduciría la lógica de desigualdad basada en el sistema de género. En este sentido, Jay Prosser (1998), un investigador transexual (de mujer a hombre), ha señalado que las narraciones transexuales y transgenéricas no muestran tanto la ficción de las categorías de género, como su continuado poder funcional: la fuerte vinculación entre los sentimientos ligados al cuerpo biológico y a su género. El poder funcional de la lógica discursiva de sexogénero se puede observar también en las subculturas gay de los bear o los leather, quienes, desde su parecido con la cultura heterosexual dominante, a veces han caído en la tentación de recuperar un discurso plumófobo, misógino y lesbófobo que restaura la 
normalidad heterosexual ${ }^{23}$ (Sáez, 2005). Asimismo, de un modo más general, el poder de redefinición simbólica de la lógica heteronormativa de sexo-género se percibe claramente en la lógica y la forma que ha asumido la pornografía actual. El relato audiovisual pornográfico ha integrado y normalizado las prácticas sexuales que fueron censuradas y estigmatizadas durante la hetero-normalización sexual del siglo XIX (Foucault, 2005) y, posteriormente, restablecidas y legitimadas por grupos LGTB+ durante el último cuarto del pasado siglo (sexo oral, fetichismo, sadomasoquismo, masoquismo, etc.). De nuevo, estas prácticas son concebidas dentro de la estructura tradicional de dominación/sumisión que asocia al varón con el sujeto de la transgresión y a la mujer con el objeto de la misma. Esta representación constituye la norma que los mecanismos occidentales de definición social están imponiendo a través de la generalización del discurso pornográfico, con su representación hipersexualizada de las mujeres y su banalización de la violencia sexual (Walter, 2010).

Finalmente, las pretensiones políticas de la teoría queer, con su crítica de los principios éticos universales y de las políticas de representación, hacen prácticamente imposible que se pueda construir un marco normativo de justicia desde su lógica interna. Esto no implica que sus estrategias políticas concretas no tengan lugar ni reconocimiento en la lucha general contra la desigualdad y la discriminación, pero esta lucha no puede renunciar nunca al principio democrático de Igualdad como eje fundamental de transformación social. Téngase en cuenta que la libertad requiere de unas condiciones de equidad social entre la ciudanía para que las personas puedan ejercerla como tal. Es decir, sin igualdad (de derechos, de oportunidades, de acceso a la educación y a los recursos materiales básicos...), no puede existir libertad.

\section{Conclusiones}

Las luchas feministas del pasado siglo XX tuvieron al principio de Igualdad como principal eje articulador de transformación social. Las vindicaciones del feminismo igualitarista se articularon fundamentalmente desde el lenguaje de los derechos, denunciando tanto la injusta exclusión de las mujeres de la ciudadanía política (en aras del derecho a la igualdad), como la consiguiente dominación social que esta exclusión política generaba. Sus frutos han sido numerosos y de valiosa importancia para el desarrollo democrático de nuestras sociedades: el acceso de las mujeres al mercado de trabajo, su reconocimiento como ciudadanas, la incorrección política de los discursos machistas, la obtención de derechos y libertades sexuales y reproductivas... Es importante apuntar que muchos hombres reconocieron la justicia de estos cambios (aunque no siempre participaran activamente en los mismos) y que algunos participaron

\footnotetext{
${ }^{23}$ Ellos se identificarían como los gays auténticos (el gay masculino) frente a los afeminados y las mujeres.
} 
en diversa medida (principalmente en el discurso político-social y de modo más rezagado y minoritario en la práctica cotidiana de la corresponsabilidad). Si los hombres reconocieron la justicia de este cambio, es porque se identificaron como iguales a las mujeres a través de la noción iusnaturalista de Igualdad como equivalencia ${ }^{24}$, una noción que se sustenta en el universalismo ilustrado y en su consiguiente proyecto político democrático (Scott, 2006). Este hecho histórico pondera el valor de los principios democráticos de Igualdad, Libertad y Solidaridad para la construcción no sólo de un marco normativo de convivencia, sino también de identidades comunes a partir de las que hombres y mujeres puedan desarrollar sentimientos de empatía y solidaridad en la práctica de la ciudadanía.

María Luisa Femenías ha señalado el valor constructivo de los principios democráticos universales, al sostener que "la ciudadanía genera identidad, conformándose íntimamente en cada sujeto como promesa de seguridad, de pertenencia y de justicia" (2011, p. 20). Tenemos así que los principios democráticos son principios abstractos desde los que reivindicar derechos universales y, simultáneamente, anclajes identitarios a partir de los cuales se pueden proyectar cambios personales dirigidos por la justicia. Encarnados en la identidad como conciencia ética de uno mismo, los principios democráticos posibilitan el reconocimiento del Otro como un igual que padece injusticias y discriminación. Por lo tanto, son una fuente de sensibilización de la cual emanan sentimientos morales como la empatía y la solidaridad. Por estos motivos, los principios democráticos se manifiestan indispensables para la articulación del cambio de los hombres hacia nuevas masculinidades igualitarias.

Los modelos de cambio propuestos por los grupos de hombres por la igualdad se han fundamentado principalmente desde los principios de Igualdad y Solidaridad. Actualmente, el modelo de cambio propuesto por estos grupos es el del hombre corresponsable y cuidador. Este modelo se construye desde el reconocimiento pragmático de que sin corresponsabilidad en el cuidado y en el trabajo doméstico no puede haber lugar para la emancipación social de las mujeres. Se origina, por lo tanto, en una cuestión de justicia, pero al mismo tiempo exige sentimientos morales que dispongan hacia el cuidado. En este sentido, Alicia Puleo (2011) ha señalado la urgente necesidad de universalizar la ética del cuidado en un mundo minado por constantes crisis sociales, ecológicas y humanitarias. El cuidado es un hábito moral basado en sentimientos de empatía y solidaridad que se origina en el reconocimiento de la mutua dependencia y vulnerabilidad humanas. Puleo propone ampliar el conjunto de los seres merecedores de respeto moral a todos los seres ecológicamente dependientes, sobre la base del reconocimiento de que las personas tenemos una común dependencia tanto de la Naturaleza como del resto de seres que participan de la misma. Aparecen así nociones como vulnerabilidad o Naturaleza, nociones que han sido históricamente desechadas del

\footnotetext{
${ }^{24}$ Noción o principio según el cual todas las personas tienen el mismo valor y, consiguientemente, los mismos derechos independientemente de su raza, sexo, clase social, religión u opción sexual.
} 
concepto patriarcal de masculinidad, contribuyendo a la socialización de los hombres en el desprecio del sufrimiento y del dolor propios, pero también y especialmente del sufrimiento y el dolor de las personas que han sido dominadas, discriminadas y sujetadas por ellos. Aceptar la propia vulnerabilidad es una condición indispensable para el cambio de los hombres hacia nuevas masculinidades. Sólo de esta forma se podrán desechar de su subjetividad las culturas del riesgo y de la violencia ligadas al modelo del hombre duro $\mathrm{y}$ viril. Este modelo ha reprimido en muchos hombres el desarrollo de emociones como la empatía o la solidaridad, emociones que son necesarias para disponer a los hombres hacia la ética del cuidado. Esto revela que el modelo del hombre cuidador y corresponsable entraña también la perspectiva del desarrollo humano ${ }^{25}$.

La perspectiva ética del desarrollo humano es importante porque el cambio de los hombres hacia nuevas masculinidades basadas en el cuidado y la justicia es un ejercicio ético de libertad personal y, por lo tanto, requiere de motivación. El principio de Igualdad puede generar sentimientos de empatía cuando se incardina en la identidad personal, pero el reconocimiento de la justicia y los sentimientos de empatía pueden ser insuficientes a la hora de generar cambios que atañen a la identidad personal. En este punto, el concepto de desarrollo humano se muestra como un elemento teleológico que puede mover a los hombres a desarrollar masculinidades más igualitarias. Es decir, a veces saber que uno está haciendo algo justo puede empujar a una persona a actuar, pero reconocerse como una persona justa y completa y que los demás te reconozcan por igual, es mucho más motivador que actuar sólo por justicia. En este sentido, entendemos que los hombres necesitan proyectar una identidad éticamente positiva desde la que accionar su cambio hacia la corresponsabilidad y el cuidado. Esta identidad se articula desde la perspectiva del desarrollo humano, pero para ser éticamente satisfactoria debe estar basada en la perspectiva de la justicia.

Martha Nussbaum ha dedicado gran parte de su trabajo a la relación entre la ética de la justicia y la perspectiva del desarrollo humano. Nussbaum (2000) señala que unas normas universales mínimas de justicia que protejan la dignidad de los seres humanos deben ofrecer a los ciudadanos un grado básico de su capacidad humana. La posibilidad del desarrollo humano es una condición sin la cual no es posible formular un criterio viable de justicia. Además, retomando un aristotelismo matizado, Nussbaum reivindica el valor de las emociones morales (la empatía, la compasión, la amistad, etc.) tanto para el desarrollo de las afiliaciones políticas de los ciudadanos en la búsqueda de su propio concepto del bien, como para el ejercicio de acciones solidarias en la búsqueda de la justicia. En este sentido, Nussbaum encuentra en las emociones morales una base de racionalidad política sobre la que poder anclar el desarrollo humano de todas las personas en la comunidad global.

\footnotetext{
${ }^{25}$ En otro lugar (Sambade, 2014), he sostenido que el cambio de los hombres hacia masculinidades igualitarias debe estar fundamentado tanto por éticas teleológicas o éticas del bien, como por éticas deontológicas o éticas de la justicia.
} 
Las tesis de Nussbaum sobre el desarrollo humano se muestran significativas en relación con el cambio de los hombres hacia nuevas e igualitarias masculinidades. En primer lugar, porque la idea de cambiar hacia modelos de desarrollo humano es un elemento de motivación personal para los hombres (más aun cuando éstos han reconocido la justicia de la igualdad social entre los sexos). Además, la teoría de Nussbaum ensalza el valor que las emociones tienen en la generación tanto de acciones motivadas por la justicia, como de acciones motivadas por el bien, entendido este como un fin propio y colectivo. Esto nos asegura que el modelo ético de cambio va a estar encarnado en la realidad humana, recuperando así para los hombres el derecho a sentirse vulnerables y a ser emotivos; a reconocer en sí mismos una condición humana que fue negada por la mística patriarcal de la masculinidad y su dialéctica excluyente masculino (Cultura) / femenino (Naturaleza). Finalmente, Nussbaum no delimita el contorno sustantivo del desarrollo humano, sino que formula unas capacidades básicas que deben ser protegidas desde principios formales de justicia definidos por su capacidad inclusiva. Esto nos permite asegurar que los modelos de cambio hacia nuevas masculinidades no se representarán desde un concepto del bien excluyente, desde una nueva masculinidad esencializada que pueda imponer un régimen de relaciones de poder. Por el contrario, las nuevas masculinidades serán identidades políticamente complejas; identidades que, encauzadas por los vectores de la justicia desde los principios democráticos, se mostrarán abiertas hacia la pluralidad, admitiendo la diversidad cultural, racial, de clase y orientación sexual.

En conclusión, los principios democráticos se postulan como una fuente de racionalidad práctica que articula la posibilidad plural del desarrollo humano en relación con cuestiones morales de justicia. Esta racionalidad se encuentra anclada en las emociones morales que emanan del reconocimiento del Otro como un igual. Es decir, en la identidad compartida que emerge de la ciudadanía para reconocer la equivalencia de todas las personas como seres humanos. Sólo desde esta perspectiva, se puede fundamentar el cambio de los hombres hacia masculinidades más justas e igualitarias, hacia masculinidades basadas en el cuidado, la corresponsabilidad y el rechazo de la violencia. 


\section{Referencias}

Badinter, E. (1993). XY. La identidad masculina (trad. Monserrat Casals). Madrid: Alianza Editorial.

Beauvoir, S. (1981). El segundo sexo. Buenos Aires: Siglo Veinte (Trabajo original publicado en 1949).

Bly, R. (1990). Iron John. Reading: Addison-Wesley Publishing Company.

Bonino, L. (2008). Hombres y violencia de género. Más allá de los maltratadores y de los factores de riesgo. Madrid: Ministerio de Trabajo e Inmigración, Subdirección General de Información Administrativa y Publicaciones.

Bourdieu, P. (2005). La dominación masculina (trad. Joaquín Jordá). Barcelona: Anagrama.

Butler, J. (1990). Gender trouble: feminism and the subversion of identity. Londres: Routledge.

Butler, J. (1993). Imitation and gender insubordination. En: H. Abelove (ed.). (1993). The Gay and Lesbian Studies Reader. Londres: Routledge.

Butler, J. (2004). Lenguaje, poder e identidad (trad. J. Sáez \& B. Preciado). Madrid: Síntesis.

Butler, J. (2008). Cuerpos que importan. Sobre los límites materiales y discursivos del "sexo" (trad. Alcira Bixio). Buenos Aires: Paidós.

Connell, R. W. (1995). Masculinities. Sydney: Polity Press, Allen \& Unwin.

Connell, R. W. y Masserschimidt, J. (2005). Hegemonic Masculinity: Rethinking the Concept. Londres: Gender \& Society, 19, 829-859.

Connell, R.W. (1997). La organización social de la masculinidad (trad. Oriana Jiménez). En: Valdés, T. y Olavarría, J. (1997). Masculinidad/es: poder y crisis. ISISFLACSO.

Clare, A. (2002). La masculinidad en crisis (trad. Irene Cifuentes). Madrid: Taurus.

Femenías, M. L. (2003). Judith Butler: Introducción a su lectura. Buenos Aires: Catálogos.

Femenías, M. L. (2008). Identidades esencializadas/violencias activadas. Madrid: ISEGORÍA, 38, 15-38.

Foucault, M. (2005). Historia de la sexualidad. Tomo I. La voluntad de saber (trad. Julia Varela y Fernando Álvarez Uría). Madrid: Siglo XXI.

Fraisse, G. (1991). Musa de la razón. La democracia excluyente y la diferencia de los sexos (trad. Alicia Puleo). Madrid: Editorial Cátedra. 
Gilmore, D. D. (1994). Hacerse hombre: concepciones culturales de la masculinidad. Buenos Aires: Paidós.

Halberstam, J. (1998). Female Masculinity. Duke: Duke University Press.

Harris, M. (1981). Introducción a la antropología general. Madrid: Alianza Editorial. (Trabajo original publicado en 1971).

Jabardo, M. (2012). Feminismos negros. Una antología. Madrid: Traficantes de Sueños.

Kimmel, M. (2008). Los estudios de la masculinidad: una introducción. En: Carabí, Àngels y Armengol, Josep M. (eds.). La masculinidad a debate. Barcelona: Icaria.

Marqués, J.V. y Osborne, R. (1991). Sexualidad y sexismo. Madrid: UNED, Fundación Universidad-Empresa.

Miedzian, M. (1995). Chicos son, hombres serán. Madrid: Horas y Horas.

Millett, K. (1975). Política sexual (trad. Ana María Bravo García). Madrid: Editorial Cátedra.

Nussbaum. M. (2000). Women and Human Development: The Capabilities Approach. Cambridge: CUP.

Preciado, B. (2002). Manifiesto contra-sexual. Madrid: Editorial Opera Prima.

Pronger, B. (1998). On your kness; carnal kwonlegde, masculine dissolution, doing feminism. En: Tom Digby (ed.). Men doing feminism. Londres: Routledge.

Prosser, Jay (1998). Second Skins: The Body Narratives of Transsexuality. Nueva York: Columbia University Press.

Puleo, A. H. (2011). Ecofeminismo para otro mundo posible. Madrid: Editorial Cátedra.

Sáez, J. (2005). Excesos de la masculinidad: la cultura leather y la cultura de los osos. En: Grupo de trabajo Queer (ed.). El eje del mal es heterosexual. Figuraciones, movimientos y prácticas feministas queer. Madrid: Traficantes de sueños.

Sambade, I. (2010). La pragmática masculina del control: del gobierno de sí mismo hacia la violencia contra las mujeres. Santiago: Nomadías, 11, 42-68.

Sambade, I. (2014). Sobre las contradicciones de la razón moderna y la constitución de la subjetividad masculina. Madrid: Prisma Social, 13, 787-851.

Sapolsky, Robert (1997). The trouble with testosterone and Other Essays. Nueva York: Simon \& Shuster.

Scott, J. W. (2006). El movimiento por la paridad: un reto al universalismo francés. En: Borderías, C. (ed.). Joan Scott y las políticas de la historia. Barcelona: Icaria.

Segal, L. (1990). Slow motion: Changing masculinities, changing men. Nueva Jersey: Rutgers University Press. 
Segal, L. (2008). Los hombres tras el feminismo ¿Qué queda por decir?. En: Carabí, Àngels \& Armengol, Josep M. (eds.). La masculinidad a debate. Barcelona: Icaria.

Seidler, V. (2000). La sinrazón masculina. Buenos Aires: Paidós.

Thomas, C. (ed.) (2000). Straight with a twist: queer theory and the subject of heterosexuality. Champaign: University of Illinois Press.

Walter, N. (2010). Muñecas vivientes. El regreso del sexismo (trad. María Álvarez Rilla). Madrid: Editorial Turner. 